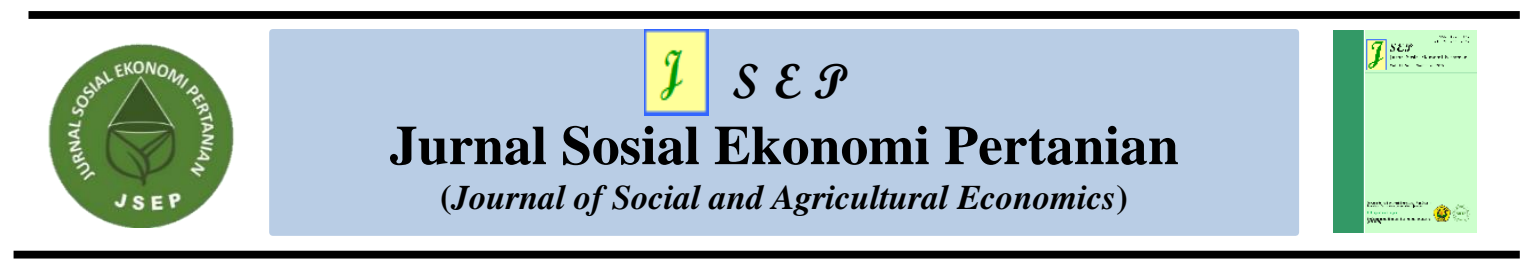

\title{
ANALISIS FAKTOR-FAKTOR YANG MEMPENGARUHI PENDAPATAN PETERNAK RAKYAT SAPI POTONG DI KECAMATAN LAMPASIO KABUPATEN TOLITOLI PROVINSI SULAWESI TENGAH
}

\section{ANALYSIS ON THE INFLUENCING FACTORS OF SMALL BEEF CATTLE FARMERS' INCOME IN LAMPASIO DISTRICT, TOLITOLI, CENTRAL OF SULAWESI}

\author{
Ibrahim $^{1 *}$, Supamri ${ }^{1}$ dan Zainal ${ }^{2}$ \\ ${ }^{1}$ Program Studi Peternakan Fakultas Peternakan Universitas Madako Tolitoli \\ ${ }^{2}$ Program Studi Peternakan Fakultas Peternakan dan Perikanan Universitas Tadulako \\ *email: ibrahimhamzah786@gmail.com
}

Naskah diterima: 02/07/2020 Naskah direvisi:10/10/2020 Naskah diterbitkan: 30/11/2020

\begin{abstract}
This research aims to determine the factors affected the income of farmer in business of beef cattle in Lampasio district, Tolitoli regency. This research applied purposive sampling technique in choosing sample. There were 36 selected sampless as respondents of three districts: Sibea, Lampasio, and Tinading. The observed variables were the characteristics of respondents' income such as breeders' age. Level of education, number of family, and farming experinence. The multiple regression was employed to find out the significant effect of the farmer income. The result showed that farmer age is old with low education level, with more than 7 years experience. The coefficient value of $R$ by 0,131which means that observed variables was 13,1\% whereas the value of unobserved variables in this research was 86,9\%. Eventhough there is no significant variable effect to farmer income, the education effects positvively to farmer income.
\end{abstract}

Keywords: income, beef cattle, multiple regression

\begin{abstract}
ABSTRAK
Penelitian ini bertujuan untuk mengetahui seberapa banyak faktor yang mempengaruhi pendapatan peternak dalam mengembangkan usaha sapi potong di Kecamatan Lampasio Kabupaten Tolitoli. Dalam penelitian ini menggunakan metode purposive sampling dalam mengambil sampel sebanyak 36 responden di tiga desa yaitu Sibea, Lampasio, dan Tinading. Variabel yang di amati adalah karakteristik pendapatan responden yang berpengaruh pada pendapatan seperti umur peternak, tingkat pendidikan, jumlah tanggungan keluarga, dan pengalaman beternak. Untuk mengetahui tingkat pengaruh variabel independen terhadap variabel dependen di gunakan analisis regresi berganda. Hasil analisis regresi menunjukkan bahwa nilai koefisien $\mathrm{R}^{2}$ sebesar 0,131 . Artinya sebesar $13,1 \%$ pendapatan dapat di jelaskan berdasarkan variabel umur peternak, tingkat pendidikan, pengalaman beternak, jumlah tanggungan keluarga. Sedangkan 86,9\% di pegaruhi oleh variabel lain yang tidak di amati pada penelitian ini. Selanjutnya berdasarkan hasil analisis parsial diketahui bahwa tidak ada variabel yang berpengaruh signifikan terhadap pendapatan. Namun demikian diketahui bahwa variabel pendidikan memiliki kecenderungan positif.
\end{abstract}

Kata kunci: pendapatan, sapi potong, regresi berganda

How to Cite: Ibrahim, Supamri dan Zainal. (2020). Analisis Faktor-Faktor yang Mempengaruhi Pendapatan Peternak Rakyat Sapi Potong di Kecamatan Lampasio Kabupaten Tolitoli Provinsi Sulawesi Tengah. JSEP: Jurnal Sosial Ekonomi Pertanian, 13(3):307-315. 


\section{PENDAHULUAN}

Beternak sudah tidak asing bagi sebagian besar masyarakat diseluruh wilayah Indonesia, begitu juga di Kecamatan Lampasio usaha peternakan sapi telah dilakukan sejak lama hingga saat ini. Pengembangan ternak sapi di daerah Kecamatan Lampasio terbilang cukup menjanjikan dengan didukung kondisi topografi yang cukup baik bagi peternakan sapi.

Partisipasi masyarakat dalam meningkatkan keberhasilan dunia peternakan sangat menentukan eksistensi usaha peternakan, sehingga dapat memberikan nilai pendapatan yang lebih untuk terus meningkatkan dan bersemangat dalam menjalankan usaha peternakan, khususnya peternakan sapi dimana ternak sapi dengan kondisi fisiologis yang lebih besar memungkinkan membutuhan yang lebih di banding dengan ternak kecil lainnya, sehingga dibutuhkan usaha ekstra agar dapat terus berjalan dan berkembang dengan baik (Harmoko dan Padang, 2019).

Masyarakat pedesaan umumnya beternak hanya sebagai usaha sambilan dikala waktu luang ataupun hanya sebagai tabungan dikala membutuhkan modal. Oleh karena itu, perkembangan usaha peternakan masyarakat cenderung lambat bahkan tidak berkembang, sehingga diperlukan dorongan lebih yang bersifat motivasi dalam mengembangakan peternakan sapi agar perkembangan usaha peternakan sapi rakyat terus menjadi salah satu sumber ternak bagi negara kita salah satunya adalah pendapatan peternak yang tinggi (Ditjen_Peternakan, 2008).

Perkembangan usaha peternakan ini merupakan sebuah hal yang positif dan harapan baru bagi peningkatan kesejahteraan masyarakat peternak tentunya dengan meningkatnya pendapatan. Hal tersebut tentunya harus disertai dengan adanya sebuah manajemen pengelolaan usaha peternakan yang tepat, baik disisi teknis maupun dalam manajemen pemasarannya (Hoddi, et al. 2011).

Usaha ternak sapi potong dapat dikatakan berhasil bila telah memberikan kontribusi pendapatan dan dapat memenuhi kebutuhan hidup peternak sehari-hari. Hal ini dapat dilihat dari berkembangnya jumlah kepemilikan ternak, dan meningkatkannya tambahan pendapatan keluarga. Pembangunan peternakan mempunyai prospek yang baik dimasa depan, karena permintaan akan bahan-bahan yang berasal dari ternak akan terus meningkat seiring dengan peningkatan jumlah penduduk, pendapatan, dan kesadaran masyarakat untuk mengkomsumsi pakan bergizi tinggi sebagai pengaruh dari naiknya tingkat pendidikan rata-rata penduduk (Santoso,1997).

Kecamatan Lampasio memiliki sumberdaya manusia dan sumberdaya alam yang cukup bagi perkembangan peternakan sapi, hal ini terlihat dari topografi dan masyarakatnya yang gemar memelihara ternak sapi. Ternak sapi di Kecamatan Lampasio hingga kini berjumlah 3523 ekor (BPS, 2019). Jumlah ternak sapi yang relatif besar tersebut jika tidak di kelolah dengan baik memungkinkan hanya akan memberikan dampak kurang baik bagi perkembagan peternakan sapi di Kecamatan Lampasio. Tatakelolah tersebut bukan hanya dari manajemen ternaknya saja, namum dari segi peternaknya juga perlu dikelolah dengan baik sehingga mereka para peternak sapi merasa memiliki tumpuan dalam usaha mengembangan peternakan sapi mereka, dalam hal ini diperlukan tingkat ketelitian lebih agar potensi jumlah ternak tersebut tidak tersiasiakan begitu saja (Afriani et al., 2014; Harmoko et al., 2020).

Penelitian mengenai pendapatan peternak sudah pernah dilakukan, namun kebaharuan penelitian ini adalah selain menganalisis mengenai pendapatan peternak, peneliti menganalisis faktor-faktor yang mempengaruhi pendapatan peternak sapi potong. Selain itu, penelitian pendapatan peternak sapi potong di Kabupaten Tolitoli masih jarang 
dilakukan. Sehubungan penjelasan tersebut maka penulis merasa perlu mengangkat permasalahan ini untuk diteliti dan dikaji secara mendasar tentang pendapatan peternak sapi potong di Kecamatan Lampasio Kabupaten Tolitoli dengan tujuan untuk mengetahui seberapa banyak faktor yang mempengaruhi pendapatan peternak dalam mengembangan usaha peternakan sapi dalam masyarakat.

\section{METODE PENELITIAN}

\section{Waktu dan Tempat}

Penelitian ini telah dilaksanakan di Kecamatan Lampasio Kabupaten Tolitoli pada tanggal 21 Maret - 05 April 2020. Pemilihan tempat penelitian secara purposive karena Kecamatan Lampasio memiliki sumberdaya manusia dan sumberdaya alam yang cukup bagi perkembangan peternakan sapi, hal ini terlihat dari topografi dan masyarakatnya yang gemar memelihara ternak sapi. Ternak sapi di Kecamatan Lampasio hingga kini berjumlah 3523 ekor (BPS, 2019).

\section{Metode}

Metode penelitian yang digunakan adalah metode survey dimana sampel penelitian ini yaitu 36 peternak sapi di Kecamatan Lampasio, sedangkan penentuan sampel dilakukan secara purposive sampling dimana sampel dipilih berdasarkan ciri-ciri khusus yang sesuai dengan tujuan penelitian sehingga diharapkan dapat menjawab permasalahan penelitian. Jenis data penelitian bersifat deskriptif yang bersumber dari data primer dan data skunder, sedangkan data penelitian didapatkan melalui observasi, wawancara dan dokumentasi.

Variabel yang diamati adalah dan variabel independen (X) dan variable dependen (Y). Variabel independen dalam penelitian ini meliputi faktor-faktor yang diduga mempengaruhi tingkat pendapatan peternak diantaranya umur, pendidikan, jumlah tanggungan keluarga, dan pengalaman beternak. Sedang variabel dependen adalah pendapatan.

Data penelitian di analisis menggunakan analisis kuantitatif dengan menggunakan tabel frekuensi persentase (\%), kemudian diinterpretasikan sesuai maksud dan tujuan penelitian. Kemudian untuk menguji tujuan kedua digunakan analisis regresi berganda. Dalam uji regresi berganda, analisis ditujukan untuk mengetahui variabel independen yang berpengaruh terhadap variabel dependen dengan persamaan regresi sebagai berikut (Gujarati, 2004). Variabel independen yang dipilih adalah variabel demografi, bukan variabel ekonomi. Hal ini diasumsikan bahwa kondisi ekonomi peternak di wilayah tersebut cenderung homogen.

$\mathbf{Y}=\mathbf{a}+\beta_{1} \mathbf{X}_{1}+\beta_{2} \mathbf{X}_{2}+\beta_{3} \mathbf{X}_{3}+\beta_{4} \mathbf{X}_{4}+\mathrm{e}$

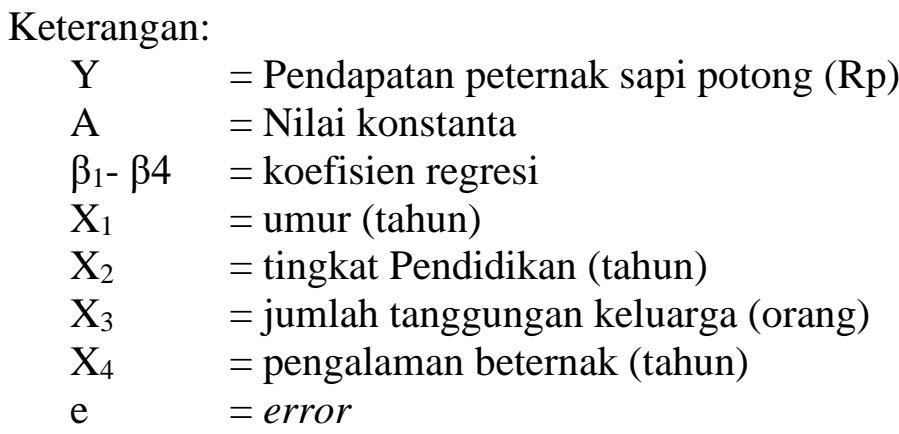


Guna mengetahui dan menguji apakah variabel penjelas secara bersama-sama berpengaruh nyata atau tidak variabel dependen digunakan uji statistik F. Selanjutnya, uji statistik t digunakan untuk menguji apakah variabel penjelas secara parsial berpengaruh nyata atau tidak terhadap variabel endogen. Adapun hipotesa uji statistik-F yang digunakan:

$\mathrm{H}_{0}=\mathrm{b}_{0}+\mathrm{b}_{1}+\ldots+\mathrm{bi}=0 ; \mathrm{H}_{1}=$ minimal ada satu $\mathrm{b}_{1} \neq 0$

Keterangan : Apabila nilai probabilitas (p-value) pada uji statistik $\mathrm{F}<\operatorname{taraf} \alpha$, maka $\mathrm{H}_{0}$ tolak. $\mathrm{H}_{0}$ ditolak berarti variabel penjelas secara bersama-sama berpengaruh nyata terhadap variabel dependen. Adapun hipotesa uji satatistik t yang digunakan yaitu :

$\mathrm{H}_{0}=\mathrm{b}_{0}=0$ dan $\mathrm{H}_{1} \mathrm{H} 1=$ uji satu arah. a) $\mathrm{b}_{1}>0$; b) $\mathrm{b}_{1}<0$

Kriteria uji : Jika $\mathrm{b}_{1}>0$, bila p-value uji $\mathrm{t}<\alpha$, maka disimpulkan tolak $\mathrm{H}_{0}$. Jika $\mathrm{b}_{1}<0$, bila $\mathrm{p}$-value uji $\mathrm{t}<\alpha$, maka disimpulkan tolak $\mathrm{H}_{0}$.

\section{HASIL DAN PEMBAHASAN}

\section{Karakteristik Peternakan Sapi Potong di Kecamatan Lampasio}

Responden penelitian adalah peternak sapi yang berdiam di Kecamatan Lampasio diantaranya adalah Desa Sibea, Desa Lampasio, dan Desa Tinading. Karakteristik peternak sapi meliputi umur peternak, tingkat pendidikan, jumlah tanggungan keluarga, dan pengalaman beternak dapat disajikan pada Tabel 1 .

Tabel 1. Karakteristik peternak sapi potong di Kecamatan Lampasio

\begin{tabular}{lcc}
\hline \hline Karakteristik Peternak & Jumlah Responden (Orang) & Persentase $(\%)$ \\
\hline Umur Peternak (Tahun) & 1 & 2,8 \\
$0-15$ Tahun & 24 & 66,7 \\
$15-50$ Tahun & 11 & 30,6 \\
$50-70$ Tahun & & \\
Tingkat Pendidikan & 2 & 5,6 \\
Tidak Sekolah & 17 & 47,2 \\
SD & 15 & 41,7 \\
SMP & 2 & 5,6 \\
SMA & & \\
Tanggungan Keluarga & 19 & 52,8 \\
$1-3$ Orang & 16 & 44,4 \\
$4-6$ Orang & 11 & 2,8 \\
$7-10$ Orang & & \\
Pengalaman Beternak (Tahun) & 1 & 2,8 \\
1 Tahun & 12 & 33,3 \\
$1-3$ Tahun & 8 & 22,2 \\
3 - 5 Tahun & 15 & 41,7 \\
$5-7$ Tahun & & \\
\hline
\end{tabular}

Sumber: Data Primer diolah (2020) 
Umur Peternak sapi di Kecamatan Lampasio berdasarkan survei sebesar 66,7\% berumur antara 15-50 tahun, 30,6\% berumur 50-70 tahun dan 2,8\% berumur 0-15 tahun. Sebagian besar responden dalam penelitian ini merupakan usia produktif, oleh karena itu diharapkan para peternak dapat lebih optimal dalam mengelola usaha peternakan serta dapat lebih mudah dan cepat dalam menyerap teknologi pemeliharaan sapi. Peternak dengan umur 15-55 tahun memberikan indikasi petani peternak termasuk dalam usia produktif untuk bekerja (Hermanto, 2006).

Peternak dalam usia produktif mampu menerima adanya peningkatan keterampilan dan pengetahuan melalui penyuluhan dan pengenalan teknologi. (Hendrayani \& Febrina, 2009) menyatakan bahwa dalam bekerja diperlukan kondisi tubuh yang sehat dan pemikiran yang matang, semakin tinggi usia semakin menurun juga kemampuan mengadopsi suatu inovasi dan untuk bekerja. Lebih lanjut dijelaskan bahwa umur muda hingga setengah tua atau usia produktif lebih mudah menerima inovasi baru. Seseorang pada usia produktif kondisi fisik, tindakan serta kemampuan berfikir cukup baik, kondisi emosional pada usia ini relative stabil sehingga mudah menerima pengarahan dan inovasi dari pihak- pihak yang lebih menguasai hal tersebut, dan didukung oleh adanya dorongan yang cukup kuat untuk memperoleh pengalaman pada usia itu (Setiana, 2000). Sirajuddin (2007) mengemukakan bahwa usia adalah salah satu faktor yang mempengaruhi produktivitas seseorang. Seseorang yang berada pada usia produktif yang tersedia produktivitasnya lebih tinggi daripada mereka yang berada di luar usia produktif.

Peternak sapi potong di Kecamatan Lampasio rata-rata memiliki tingkat pendidikan tamat SD 47,2\%, SMP sebanyak 41,7\%, tingkat pendidikan lulus SMA 5,6\%, dan tidak sekolah sebanyak $5,6 \%$. Berdasarkan data di atas bahwa tingkat pendidikan peternak sapi potong di Kecamatan Lampasio masih relative rendah, akan tetapi pada prakteknya tingkat pendidikan tidak begitu berpengaruh terhadap pelaksanaan kegiatan beternak sapi di Kecamatan Lampasio, hal ini karena keuletan dan kerja keras para peternak yang menjadikan mereka tetap berkualitas. Pengetahuan beternak yang dimiliki oleh para peternak biasanya di dapatkan secara turun temurun, hal ini karena tidak ada peternak yang secara khusus mempelajari dunia peternakan melalui pendidikan formal.

Pendidikan sangat mempengaruhi kualitas sumberdaya manusia, dalam hal ini kaitannya dengan peternakan sapi potong di Kecamatan Lampasio, akan tetapi yang menjadi tolak ukur adalah keuletan dan kerja keras dalam beternak sapi. Menurut (Mosher, 2007), bahwa pendidikan peternak merupakan pelancar pembangunan pertanian karena dengan pendidikan petani mengenal pengetahuan, keterampilan dan cara baru dalam melakukan kegiatan usaha.

(Alam et al., 2014) menyatakan bahwa tingkat pendidikan yang baik akan cenderung mudah untuk menerima informasi baru dalam teknik beternak yang baik, selain memberikan tanggapan positif pada setiap kemajuan usaha beternak juga lebih matang untuk memecahkan setiap permasalahan yang dihadapinya. Semakin tinggi tingkat pendidikan peternak akan sangat berpengaruh terhadap daya piker dan pemahaman tentang materi penyuluhan dan inovasi ilmu pengetahuan, keterampilan dan carabaru dalam melakukan kegiatan usaha. Tingkat pendidikan yang tinggi berpengaruh pada kecepatan untuk mengadopsi inovasi, memahami sifat dan fungsi inovasi (Kusnadi et al., 2005).

Berdasarkan data penelitian diatas bahwa tanggungan keluarga peternak sapi potong di Kecamatan Lampasio persentase sebanyak 52,8\% tanggungan 1-3 orang, 44,4\% tanggungan 4-6 orang, dan 2,8\% tanggungan keluarga 7-10 orang. Ini menandakan makin banyak jumlah tanggungan keluarga semakin mengurangi pendapatan beternak, atau 
makin sedikit jumlah tanggungan keluarga semakin meningkat pendapatan peternak sapi potong. (Siregar, 2009) menyatakan bahwa sebagian peternak kurang memiliki motivasi karena kurang gagasan/ide yang juga berbenturan dengan besarnya jumlah tangggungan keluarga. (Harmoko, 2017) menambahkan semakin sedikit jumlah anggota keluarga maka akan meningkatkan pendapatan peternak. Petani dengan jumlah anggota kelurga yang kecil cenderung memiliki motivasi yang besar untuk beternak sapi potong dan meningkatkan pendapatan. (Ahmadi, 2003) menyatakan bahwa masyarakat peternak itu mula-mula terdiri dari small family (keluarga kecil) yaitu suatu keluarga yang terdiri dari ayah, ibu, dan anaknya paling banyak 2 atau 3 orang anak. Pada keluarga kecil ini biasanya yang menjadi tanggungan hidup adalah ibu dan anak-anak.

Peternak sapi potong di Kecamatan Lampasio rata-rata cukup berpengalaman dalam hal beternak, hal ini terbukti dari $41,7 \%$ responden telah mempunyai pengalaman antara 5-7 tahun, sedangkan 22,2\% mempunyai pengalaman 3-5 tahun, 33,3\% berpengalaman 1-3 tahun dan 2,8\% pengalaman beternak kurang dari 1 tahun atau baru memualai beternak sapi potong. Lama pengalaman seorang peternak dalam memelihara ternaknya dapat mempengaruhi tingkat keberhasilan dalam usahanya, karena semakin lama pengalamannya, maka pengetahuan yang diperoleh tentang seluk beluk pemeliharaan ternak semakin banyak.

Usaha peternakan sapi potong pada umumnya merupakan usaha yang dijalankan secara turun temurun dan bersifat statis, mereka mendapatkan pengalaman beternak sejak kecil dari orang tua maupun lingkungan sekitarnya. Pengalaman merupakan faktor penentu maju mundurnya kegiatan usaha (Luanmase et al., 2011). (Soekartawi, 2002) menambahkan peternak yang lebih berpengalaman akan lebih cepat menyerap inovasi teknologi dibanding dengan peternak yang belum atau kurang berpengalaman. Pengalaman bertani/beternak merupakan modal penting untuk berhasilnya suatu kegiatan usaha tani, berbedanya tingkat pengalaman masing-masing petani maka akan berbeda pula pola pikir mereka dalam menerapkan inovasi pada kegiatan usaha taninya (Hendrayani dan Febrina, 2009).

\section{Faktor yang Mempengaruhi Pendapatan Peternak Sapi Potong}

Untuk menguji faktor-faktor yang mempengaruhi pendapatan usaha ternak sapi potong di kecamatan Lampasio Kabupaten Tolitoli digunakan analisis regresi linier berganda, dimana yang menjadi variabel bebas (independent) adalah umur peternak $\left(\mathrm{X}_{1}\right)$, tingkat pendidikan $\left(\mathrm{X}_{2}\right)$, jumlah tanggungan keluarga $\left(\mathrm{X}_{3}\right)$, dan pengalaman beternak $\left(\mathrm{X}_{4}\right)$. Sedangkan yang menjadi variabel terikat (dependent) adalah pendapatan (Y). Hasil analisis regresi berganda pengaruh karakteristik peternak terhadap pendapatan tersaji pada Tabel 2.

Hasil analisis regresi pada Tabel 2 menunjukkan bahwa berdasarkan uji $\mathrm{F}$ secara bersama-sama variabel bebas yang diamati berpengaruh nyata $(\mathrm{P}<0,05)$ terhadap pendapatan. Nilai koefisien Adjusted $R$ Square $\left(\mathrm{R}^{2}\right)$ sebesar 0,131, atau nilai sebesar $13,1 \%$ artinya adalah variasi pendapatan yang dapat dijelaskan berdasarkan variabel umur peternak, tingkat pendidikan, pengalaman beternak, jumlah tanggungan keluarga, sedangkan sisanya sebesar $86,9 \%$ dipengaruhi oleh variabel lain $(\mu)$ yang tidak diamati pada penelitian ini. Namun, setelah dilakukan pengujian secara parsial diketahui bahwa tidak ada satupun variabel yang berpengaruh signifikan terhadap pendapatan. Hal ini diketahui bahwa keempat variabel tersebut memiliki probabilitas $\mathrm{P}>0,05)$. 
Tabel 2. Hasil analisis regresi berganda faktor yang mempengaruhi pendapatan peternak sapi potong

\begin{tabular}{|c|c|c|c|c|}
\hline No. & Variabel bebas (independent variable) & $\begin{array}{c}\text { Koefisien regresi } \\
\text { (regression } \\
\text { coeficcient) }\end{array}$ & $\begin{array}{l}\text { Nilai t } \\
\text { (value } t)\end{array}$ & $\begin{array}{l}\text { Probabilitas } \\
\text { (probability) }\end{array}$ \\
\hline 1. & $\begin{array}{l}\text { Umur peternak (tahun) (farmers age } \\
(\text { year)) }\end{array}$ & $-0,041$ & $-0,22^{\mathrm{ns}}$ & 0,827 \\
\hline 2. & $\begin{array}{l}\text { Tingkat pendidikan (tahun) (level of } \\
\text { education (year)) }\end{array}$ & 0,132 & $0,735^{\text {ns }}$ & 0,468 \\
\hline 3. & $\begin{array}{l}\text { Jumlah tanggungan keluarga (orang) } \\
\text { (the number of dependents family } \\
\text { (person)) }\end{array}$ & $-0,204$ & $-1,097^{\mathrm{ns}}$ & 0,282 \\
\hline 4. & $\begin{array}{l}\text { Pengalaman beternak (tahun) } \\
\text { (farmers experiences (year)) }\end{array}$ & $-0,052$ & $-0,274^{\mathrm{ns}}$ & 0,786 \\
\hline & $\begin{array}{ll}\text { : } & \text { ns : tidak signifikan } \\
& \mathrm{R}^{2}: 0,131 \\
& \mathrm{~F}: 5,903\end{array}$ & & & \\
\hline
\end{tabular}

Umur peternak $\left(\mathrm{X}_{1}\right)$ tidak berpengaruh signifikan $(\mathrm{P}>0,05)$ terhadap pendapatan dengan koefisien negatif. Hal ini dapat disebabkan karena kriteria umur peternak tidaklah mendorong kinerja peternak dalam usaha ternak sapi potong di daerah penelitian, mayoritas penduduknya mempunyai pekerjaan utama sebagai petani perkebunan. Fathoni (2004), menyatakan pada saat mencapai usia tertentu misalnya 55 tahun, 60 atau 65 tahun seorang pekerja pasti memasuki masa pensiunan atau tidak produktif lagi dalam hal bekerja. Peternak yang memiliki usia muda dan produktif akan berkerja maksimal untuk meningkatkan pendapatan.

Tingkat pendidikan $\left(\mathrm{X}_{2}\right)$ tidak berpengaruh signifikan $(\mathrm{P}>0,05)$ terhadap pendapatan. Meskpiun tidak signifikan, variabel ini memiliki arah positif. Hal ini sependapat dengan (Saleh et al., 2006) mengemukakan bahwa pendidikan yang cukup tentu dapat mendorong seseorang dalam mengatasi persoalan yang dihadapi, khususnya para peternak dalam hal peningkatan pendapatan dari usahanya. Jumlah tanggungan keluarga $\left(\mathrm{X}_{3}\right)$ tidak berpengaruh signifikan $(\mathrm{P}>0,05)$ terhadap pendapatan dengan arah negatif. Ini menandakan bahwa semakin sedikit jumlah anggota keluarga maka akan meningkatkan pendapatan peternak, artinya jika jumlah anggota keluarga kecil, maka hasil pendapatan dari beternak menguntungkan dan dapat ditabung.

Pengalaman beternak $\left(\mathrm{X}_{4}\right)$ tidak berpengaruh signifikan $(\mathrm{P}>0,05)$ terhadap pendapatan dengan koefisien negatif. Makin bertambah pengalaman beternak semakin mengurangi pendapatan, seharusnya semakin bertambah pengalaman beternak semakin meningkatkan pendapatan. Dijelaskan pula bahwa pengalaman beternak sapi potong cukup tinggi di Kecamatan Lampasio namun ternyata tidak menunjukkan tatalaksana pemeliharaan sapi yang baik, mereka lebih cenderung menggunakan metode lama secara tradisional.

\section{KESIMPULAN}

Semakin meningkat jumlah ternak sapi, pengalaman beternak maka pendapatan peternak sapi potong akan semakin tinggi sedangkan semakin banyak jumlah tanggungan keluarga maka motivasi beternak sapi potong di Kecamatan Lampasio juga akan semakin meningkat. Mengingat banyak masyarakat yang memiliki Pendidikan relatif rendah, 
disarankan bagi peternak untuk meningkatkan pendidikan informal dengan pelatihan budidaya ternak dengan memperhatikan Good Agricultural Practices (GAP).

\section{DAFTAR PUSTAKA}

Afriani, H., Idris, N., \& Fatati, F. (2014). Minat dan Motivasi Peternak untuk Mengembangkan Ternak Sapi Pada Kawasan Perkebunan Kelapa Sawit di Propinsi Jambi. Jurnal Ilmiah Ilmu-Ilmu Peternakan, 17(2), 77-83.

Ahmadi, A. H. (2003). Sosiologi Pendidikan. PT. Rineka Cipta.

Alam, A., Sumekar, S., \& Dwijatmiko, W. (2014). Motivasi Peternak terhadap Aktivitas Budidaya Ternak Sapi Potong di Kabupaten Buru Provinsi Maluku. AGRONEMA, 32(2), 75-89.

BPS. (2019). Tolitoli dalam Angka. BPS Toli-Toli.

Ditjen_Peternakan. (2008). Kajian Pola Penggembangan Peternakan Rakyat Berwawasan Agribisnis. Derektorat Jenderal Peternakan.

Fathoni, A. H., 2004. Manajemen Sumber Daya Manusia. Penerbit PT. Rineka Cipta, Jakarta.

Gujarati, D. (2004). Basics Econometrics (4th ed.). The McGraw Hill Companies.

Harmoko. (2017). Tingkat Motivasi Petani dalam Beternak Sapi di Kecamatan Sambas Kabupaten Sambas. JSEP : Jurnal Sosial Ekonomi Pertanian, 10(1).

Harmoko, H., \& Padang, P. (2019). Kondisi Performa dan Status Fisiologis Kambing Kacang dengan Pemberian Pakan Tepung Daun Jarak (Jatropha gossypifolia) Fermentasi. Jurnal Peternakan Indonesia (Indonesian Journal of Animal Science), 21(3), 183-191.

Harmoko, H., Ibrahim, I., Kusrianty, N., \& Marhayani, M. (2020). Gambaran Struktur Populasi Ternak Kambing di Kecamatan Galang Kabupaten Tolitoli. Cendekia Eksakta, 5(2).

Hendrayani, E., \& Febrina, D. (2009). Analisis Faktor-Faktor yang Dipengaruhi Motivasi Beternak Sapi di Desa Koto Benai Kecamatan Benai Kabupaten Kuantan Singingi. Jurnal Peternakan, 6(2), 53.

Hermanto, F. (2006). Ilmu Usaha Tani. Penebar Swadaya.

Hoddi, A.H, Rombe, M.B, Fahrul. 2011. Analisis Pendapatan Peternakan Sapi Potong Di Kecamatan Tanete Rilau, Kabupaten Barru. Jurusan Sosial Ekonomi Peternakan. Jurnal Agribisnis Vol. X (3), Hal 100. Fakultas Peternakan Universitas Hasanuddin. Makassar

Kusnadi, U., Diwyanto, K., \& Bahr, S. (2005). Pengembangan Sistem Usaha Tani Ternak-Tanaman Pangan Berbasis Kambing di Kabupaten Lombok Timur NTB. Prosiding Seminar Nasional Teknologi Peternakandan Veterineri Bogor, 685-692.

Luanmase, M. C., Nurtini, S., \& Haryadi, F. T. (2011). Analisis Motivasi Beternak Sapi Potong Bagi Peternak Lokal dan Transmigran Serta Pengaruhnya terhadap Pendapatan di Kecamatan Kairatu, Kabupaten Seram Bagian Barat. Buletin Peternakan, 35(2), 113-123. 
Mosher, A. T. (2007). Menggerakkan dan Membangun Pertanian. Yasguna.

Saleh, E., \& Sofyan, Y. H. 2006. Analisis Pendapatan Peternak Sapi Potong di Kecamatan Hamparan Perak Kabupaten Deli Serdang (Analysis of Income's Cattleman in Subdistrict of Hamparan Perak District of Deli Serdang). Jurnal Agribisnis Peternakan. Vol. 2 (1): 36-42.

Santoso. 1997. Prospek Agribisnis Penggemukan Pedet. Penebar Swadaya, Jakarta

Setiana, M. G. (2000). Pengenalan Jenis Hijauan Makanan Ternak Unggul. Institut Pertanian Bogor.

Sirajuddin. 2007. Faktor-faktor yang Memotivasi Peternak dalam Melakukan Kemitraan Kecamatan Bantimurung, Kabupaten Maros. Jurnal Agribisnis, Vol VI (2), Juni.

Siregar, S. A. (2009). Analisis Pendapatan Peternakan Sapi Potong Dikecamatan Stabat Kabupaten Langkat. Universitas Sumatera Utara.

Soekartawi. (2002). Prinsip Dasar Ekonomi Pertanian Teori dan Aplikasi. Raja Grafindo Persada. 